\title{
Role of the corporate sector in promoting family health in Uttar Pradesh: Implications for behavior change communication
}

Population Council

Follow this and additional works at: https://knowledgecommons.popcouncil.org/departments_sbsr-rh

Part of the Business and Corporate Communications Commons, Demography, Population, and Ecology Commons, Family, Life Course, and Society Commons, Health Policy Commons, International Public Health Commons, and the Public Health Education and Promotion Commons How does access to this work benefit you? Let us know!

\section{Recommended Citation}

Population Council. 2010. "Role of the corporate sector in promoting family health in Uttar Pradesh: Implications for behavior change communication," Shaping Demand and Practices to Improve Family Health Outcomes in Northern India Policy Brief no. 15. New Delhi: Population Council. 


\section{Role of the corporate sector in promoting family health in Uttar Pradesh: Implications for behavior change communication}

\section{Background}

With economic liberalization in the 1990s and the huge growth of the corporate sector in India, there is a growing expectation that the corporate sector should contribute to improving the quality of life of communities in the area where they are located. Indeed, many companies in India are conscious of their corporate social responsibility (CSR) and have initiated innovative community-level programs covering a range of developmentrelated activities.

The corporate sector in Uttar Pradesh (UP) has been recognized as a potential partner in complementing the behavior change communication (BCC) strategy to improve family health outcomes for several reasons. A number of industries are located in UP that have a huge captive workforce; many of these workers are relatively better educated and can be easily reached under a single umbrella of management with focused messages. Many workers are migrants from villages or small towns; as they continue to have a strong links with rural areas they could be effective channels for disseminating information on desired behaviors in rural areas. Several large corporate organizations have their own health facilities that provide services to their workers, their family members and communities in the catchment area; these facilities could be leveraged to provide information and services on desired health behaviors. Finally, the government has recommended that the corporate sector should play a proactive role in promoting inclusive growth and social and economic development in the area where they are located and has issued guidelines for CSR activities for both the public and private sector (Box 1).

In this background, in 2009 the Confederation of Indian Industry (CII), a partner in the Population Council-led Consortium, took the lead to explore (a) the role of the corporate sector in family health in UP; (b) the possibility of partnering with this sector to design, leverage and implement a BCC strategy; and (c) the support and assistance the sector would require to ensure better planning and implementation of their CSR activities. The study was funded by the Population Council as a subcontract, from an award granted by the Bill and Melinda Gates Foundation.

\section{Methodology}

To collect relevant information, CII undertook the following activities: a) an extensive literature review to document corporate sector CSR initiatives, with a special focus on UP and health-related activities; b) a detailed mapping of industries in UP to understand their spread by size and region, c) a postal survey of 310 large and cluster ${ }^{1}$ industries in UP to explore their health-related activities; d) in-depth interviews with 26 managers responsible for CSR activities in large industries to explore their interest in partnering to develop and implement the BCC strategy, the possibility of implementing copartnership models for CSR, and to identify industries that could champion the cause of family health under CSR and take the programs ahead in the future e) two regional consultations for industry stakeholders in the state to provide a forum to discuss the forementioned issues; promote networking and partnerships amongst industries for capacitybuilding to undertake CSR programs; explore

\section{Box 1: CSR budget for central public sector} enterprises

\begin{tabular}{|l|c|}
\hline Net profit of previous year & $\begin{array}{c}\text { CSR budget per year } \\
\text { (\% of net profit) }\end{array}$ \\
\hline$<$ Rs 1,000 million & $3-5 \%$ \\
\hline Rs $1,000-5,000$ million & $2-3 \%^{*}$ \\
\hline Rs 5,000 million and above & $0.5-2 \%$ \\
\hline
\end{tabular}

Note: *Subject to a minimum of Rs 30 million.

Rs 10 million $=$ US\$ 213,000 .

Source: Department of Public Enterprises, Guidelines on Corporate Social Responsibility for Central Public Sector Enterprises, dpemou.nic.in/MOUFiles/PPTonCSR.ppt

\footnotetext{
${ }^{1}$ Cluster industries are small or medium size industries located in the same city, often engaged in similar businesses.
} 
the possibility of promoting co-financing initiatives for CSR projects and the willingness of the corporate sector to partner in the proposed BCC strategy. These meetings were attended by representatives from 15 industries across the state, as well as from medical institutes, research institutes and the Government of Uttar Pradesh.

\section{Key findings}

Mapping of industries across UP: Data from the mapping exercise reveal that there are 1,700 industries located across the state ${ }^{2}$. Of these, 62 are large-scale, 366 are medium-scale and 1,281 are small-scale industries ${ }^{3,4}$. These 62 large industries are located in each of the three regions of UP and could be approached to partner in designing and implementing the BCC strategy. Most large industries (60 percent) are located in the Western region (Figure 1). However, 11-12 large industries are located in each of the other two regions.

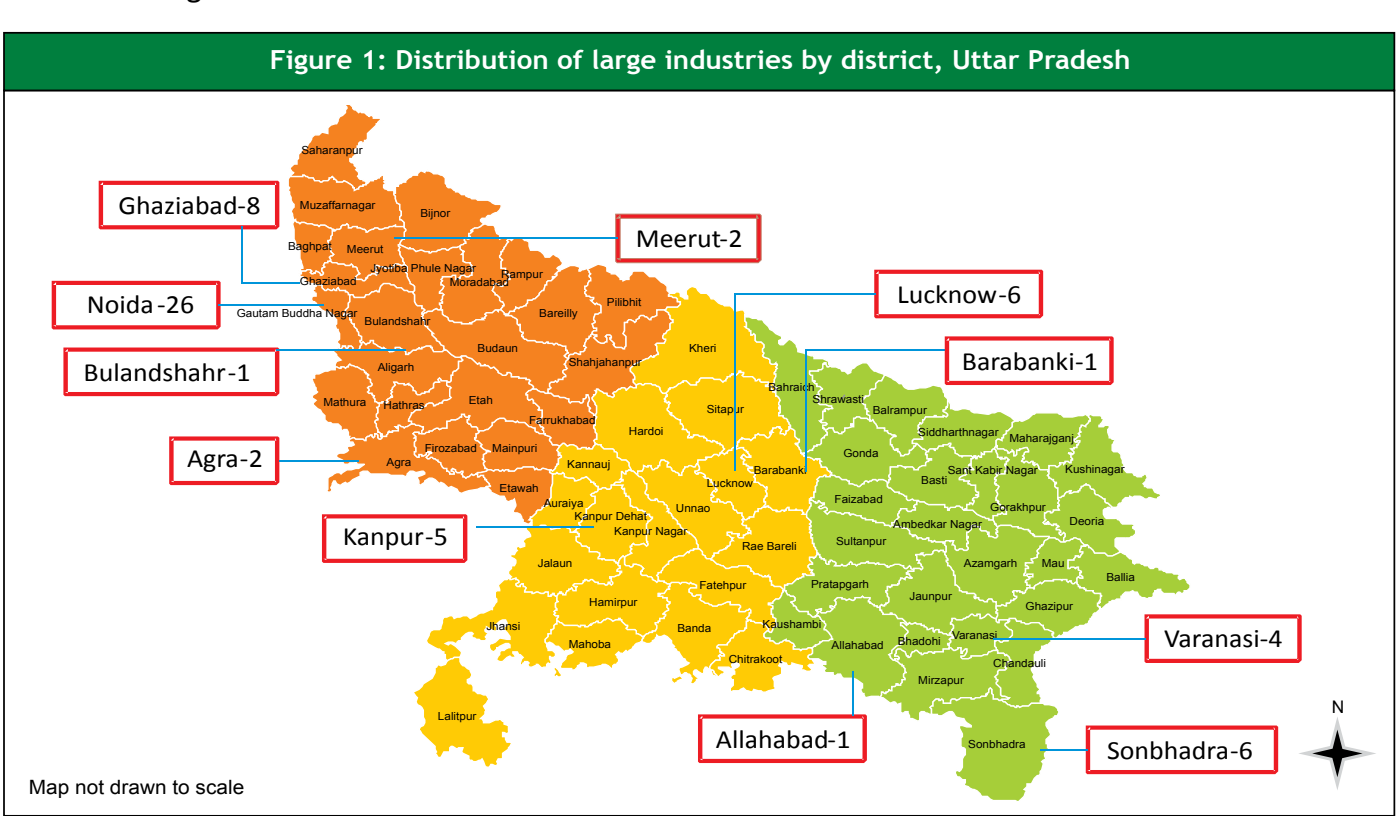

Leveraging partnerships with industry associations for CSR: CII has a large network of affiliates in UP, and could partner with 310 industries-294 CII affiliate industries and 16 non-CII affiliate industries-to take the BCC strategy ahead. Such partnerships could have a significant impact; for example, these 310 industries associated with CII employ approximately 650,000 staff. If their immediate family members are included, the population that could be benefited increases to 3.25 million.

The literature review shows that industry associations such as CII, FICCI, ASSOCHAM, are indeed working with their member industries to implement CSR programs. Industry associations could be actively involved in partnering with member industries and leveraging the strengths of their members to design and implement the BCC strategy.
Funds for CSR activities: Several industries, particularly public sector undertakings (PSUs), are spending a substantial amount on activities to benefit workers, their families and the surrounding communities. For example, the estimated CSR budget for 2007-08 of the PSU, National Thermal Power Corporation (NTPC), was Rs 140 million (US\$ 3.04 million $)^{5}$ while the CSR budget of Jubilant Organosys Ltd, a large industry located in UP, for the same period was Rs 50 million (US\$ 1.09 million) 6 .

Many CSR activities are decided on an ad hoc basis and several industries do not have the capacity to plan and implement enhanced CSR activities without some input in terms of capacity building and technical support. Further, if the capacity of willing and interested industries is built and technical support is provided, the funds available with companies for CSR programs could be effectively leveraged to implement the BCC strategy either directly by leveraging the BCC strategy, for example, buying TV time to

disseminate information, or indirectly by carrying out the activities themselves.

Decision-making on CSR policies: Interviews with corporate program mangers indicate that decisions on CSR policies and programs are taken at the highest level by the company's top managers. Initial discussions on the kind of CSR activities to be implemented are held with members of the CSR team, and the main discussion points are conveyed to the Board of Managers by the head of the CSR team. According to a manager: "The proposal for CSR activities has to be put up to the Executive Director for approval. A concept note has to be circulated to the top management for any decision to be taken." Discussions also reveal the critical need for the support and involvement of the top management in planning and implementing the proposed BCC strategy under the CSR program. It was generally believed that unless a dialogue of partnership and collaboration is held at the top management level, efforts to build partnerships may not succeed.

Coverage and reach of industries in UP: Findings from the postal survey, in-depth interviews and review of literature highlight that most large industries could be effective partners in implementing the BCC strategy given their current reach and articulated interest in the subject. For example, the 68 industries that responded to the postal survey have a large workforce of over 150,000 employees.

\footnotetext{
${ }^{2}$ GoUP, Infrastructural and Industrial Development Department, 2008.

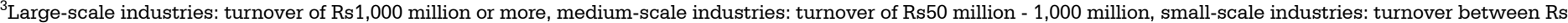
1 million - Rs 50 million.

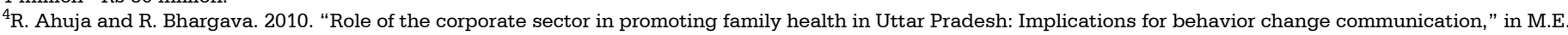

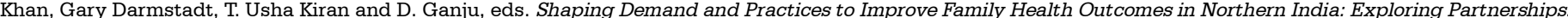
New Delhi: Population Council.

${ }^{5}$ http://www.cag.gov.in/html/reports/commercial/2009_22CA/chap_3.pdf

${ }^{6}$ http://www.karmayog.org/csr1to500/csr1to500 20477.htm.
} 
Several of these companies (33) are also providing services to communities in the catchment area, covering a population of almost four million. While large industries, on average, are covering around 30 villages each, cluster industries are covering 10 villages each.

Findings from in-depth interviews with 26 industries reveals that only 18 are implementing CSR programs in the vicinity of their operations; 18 industry managers also indicated that the CSR programs of large companies cover vast populations: 10 companies are covering a population of 25,000 or more; 3 companies are covering a population of 100,000 or more, and 3 companies are covering 100 or more villages. Hindalco Industries Ltd's CSR program supports over 232 villages around the plant in Renukoot, UP ${ }^{7}$, Noida Power Company Ltd's (NPCL) CSR activities cover 115 neighboring villages.

Health-related CSR programs: Many large industries in UP are actively providing health and family planning services to their employees and the larger community as part of the CSR program, and could easily become partners in implementing and leveraging the BCC strategy. During in-depth interviews, most industry managers whose company had a CSR program noted that they are engaged in health-related CSR activities. Managers recognized the importance of ensuring the health and well-being of their employees and their families from the perspective of productivity. According to one manager: "Health is important because it affects school attendance and workers' absenteeism. "The postal survey also shows that most industries (58 out of 68) have their own health facility, ranging from a basic health post, to mobile dispensaries and large hospitals with specialty and in-patient facilities and are providing health services to both employees and the neighboring community; providing services to both employees and their families; and or providing services only to their regular and contractual employees.

Communication strategies for dissemination of health

messages: Industries are adopting a range of methods to disseminate information on health at the workplace as well as in their outreach programs to employees and their families. Methods include inter-personal communication, one-on-one counseling during medical check-ups, displaying health messages on boards, and organizing lectures and audio-visual shows. Notably, many companies are organizing group meetings, including women's meetings, men's meetings and large village meetings to raise awareness on health issues in the community. However, none of the industries covered had a clear-cut communications strategy; their activities are planned and implemented in an ad hoc manner.
Champions of CSR: Industry champions can act as catalysts to strengthen CSR programs within and across industries and promote the cause of improving family health outcomes. During interviews and consultative workshops, 15 industries across the state were identified that are willing to champion the cause of CSR and partner in kick-starting the proposed BCC strategy. These industries are spread across the three regions (Figure 2).

Technical assistance for designing and implementing CSR programs: Industries expressed interest in developing a BCC strategy for health and articulated the need for technical assistance and capacity building to plan and implement the strategy. For example, a manager said: "Technical assistance for building a CSR strategy would be welcome. "According to another manager: "Lack of knowledge is lack of action. Inform us about the area to be adopted and give us the content; we will do our homework and will implement it."

Industries also acknowledged the need for technical assistance to monitor program activities effectively, as reflected in the comments of an industry manger: "Strong monitoring of the program is required, and we need to know what to monitor and how to monitor." Technical support for documentation of CSR activities is also reported to be a requirement.
Figure 2: Distribution of industries that can champion the cause of CSR, UP 
organizations together: "We need technical support. We are keen to undertake CSR activities. We are eager to support social causes and would like support from industry associations. "The consultation revealed that the corporate sector is open to the idea of partnering in the implementation the proposed BCC strategy, and is looking for ways they can strengthen their capability to scale up their CSR activities that are not only useful but also sustainable. As a senior manager said: "We are willing to participate in the communications strategy but it should be sustainable."

\section{Implications for the BCC strategy}

Partnerships have the potential to scale up initiatives: Findings indicate that partnering with the corporate sector in UP could be immensely beneficial in improving family health outcomes both because they cover large populations and they have the potential to leverage the BCC strategy as well as deliver services. There are many opportunities under the umbrella of CSR that could be channeled to leverage not only the BCC strategy but also social mobilization and the promotion of civil society to act as a watchdog to monitor the delivery of health services.

\section{Leveraging existing health and} communication activities: Most large industries are implementing a health program and serve, in addition their workforce and their families, large populations groups in the catchment area. Activities include social mobilization for the adoption of desired behaviors and imparting education on various aspects of heath, particularly family planning. Some industries are using innovative approaches to communicate health messages. Building on these programs, BCC strategies could develop focused messages for the eight target behaviors. Industries are interested in partnerships and expressed a desire for technical assistance to build their capacity for planning and implementing CSR activities that are based on evidence and needs rather than decisions taken on an ad hoc basis. Industry associations could play a key role in linking industries to establish copartnership/co-investment models for BCC.

Leveraging funds available under the CSR program: The government has issued voluntary guidelines on CSR for adoption by private organizations and has mandated all public sector companies to spend 1-5 percent of their net profit on CSR activities. This would make available a large reservoir of funds for CSR activities and if properly invested in the social sector, including heath, could made huge difference to communities in and around industries.

Readiness to take on the role of champions to promote family health under CSR program: Most companies articulated an interest in participating in a BCC strategy for family health. During consultations at least 15 companies expressed their desire to act as champions of the cause of CSR, and take family health programs and the BCC strategy ahead. An encouraging finding is these 15 industries are spread across all the three regions of UP-7 in the West, 2 in the Central and 6 in the Eastern region. However, to ensure success of the initiative, it would be necessary to discuss these issues at the corporate office level as decisions on CSR activities are generally taken by the top management. To take the proposed BCC strategy ahead and improve family health outcomes in rural UP, a coordination group should be set up to bring on board partners from different sectors to provide their expertise. Associations of industry can play a significant role in coordinating strategies and building partnerships among industries. Several industries have already identified the need for training and capacity-building to plan and implement CSR strategies.

Suggested citation: Population Council. 2010. Role of the corporate sector in promoting family health in Uttar Pradesh: Implications for behavior change communication, Policy Brief No. 15. New Delhi: Population Council. For additional information, contact: Population Council, Zone 5A, India Habitat Centre, Lodi Road, New Delhi 110003, or email info-india@popcouncil.org, or contact Confederation of Indian Industry ( CII), 249-F, Sector 18,Udyog Vihar, Phase IV, Gurgaon-122015, Haryana

\section{(2) Population Council}

Research that makes a difference

\section{Abt}

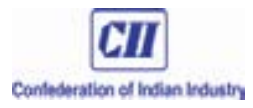

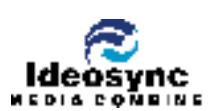
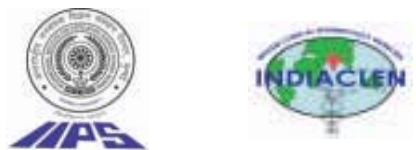

$\begin{array}{ll}\mathbf{k} & \mathbf{B} \\ \mathbf{s} & \mathbf{B} \\ \mathbf{W} & \mathbf{D} \\ \mathbf{A} & \mathbf{0} \\ \mathbf{M} & \mathbf{O} \\ \mathbf{Y} & \end{array}$

The opinions expressed in this publication do not necessarily reflect the views of the funding agencies.

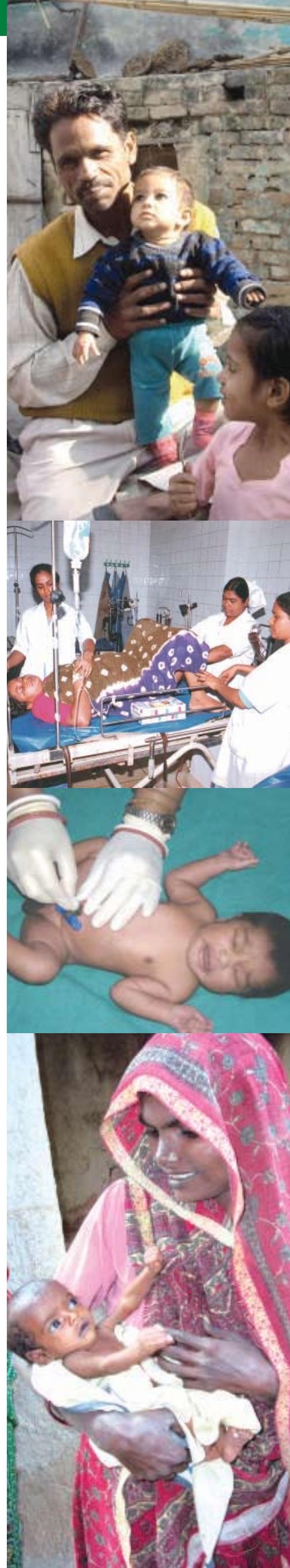

